\title{
Impact of Sea-Spray on the Atmospheric Surface Layer
}

\author{
L. Bianco · J.-W. Bao - C. W. Fairall • S. A. Michelson
}

Received: 5 May 2010 / Accepted: 15 April 2011 / Published online: 14 May 2011

(C) The Author(s) 2011. This article is published with open access at Springerlink.com

\begin{abstract}
The feedback effects of sea-spray on the heat and momentum fluxes under equilibrium conditions associated with winds of tropical cyclones are investigated using a onedimensional coupled sea-spray and atmospheric surface-layer (ASL) model. This model is capable of simulating the microphysical aspects of the evaporation of saline water droplets of various sizes and their dynamic and thermal interaction with the turbulence mixing that is simulated by the Mellor-Yamada 1.5-order closure scheme. Sea-spray droplet generation is described by a state-of-the-art parametrization that predicts the size spectrum of sea-spray droplets for a given surface forcing. The results from a series of simulations indicate the way in which evaporating droplets of various sizes modify the turbulence mixing near the surface, which in turn affects further droplet evaporation. All these results are direct consequences of the effects of sea-spray on the balance of turbulent kinetic energy in the spray-filled surface layer. In particular, the overall impact of sea-spray droplets on the mean wind depends on the wind speed at the level of sea-spray generation. When the wind speed is below $40 \mathrm{~m} \mathrm{~s}^{-1}$, the droplets are small in size and tend to evaporate substantially and thus cool the spray-filled layer, while for wind speeds above $50 \mathrm{~m} \mathrm{~s}^{-1}$, the size of the droplets is so large that they do not have enough time to evaporate much before falling back into the sea. The sensible heat carried by the droplets is released to the ambient air, increasing the buoyancy of the surface layer and enhancing the turbulent mixing. The suspension of sea-spray droplets reduces the buoyancy and makes the surface layer more stable, decreasing the friction velocity and the downward turbulent mixing of momentum. The results from the numerical experiments also suggest that, in order not to violate the constant flux assumption critical to the MoninObukhov similarity theory, a displacement equal to the mean wave height should be included in the logarithmic profiles of the wind and thermal fields.
\end{abstract}

L. Bianco $(\varangle) \cdot$ J.-W. Bao · C. W. Fairall · S. A. Michelson

Earth Systems Research Laboratory, National Oceanic and Atmospheric Administration, 325 Broadway,

Mail Stop: PSD3, Boulder, CO 80305, USA

e-mail: Laura.Bianco@noaa.gov

L. Bianco $\cdot$ S. A. Michelson

Cooperative Institute for Research in the Environmental Sciences, University of Colorado, Boulder, CO, USA 
Keywords Air-sea interaction · Atmospheric surface layer · Sea-spray ·

Surface boundary layer

\section{Introduction}

The potential effects of sea-spray on the atmospheric surface-layer (ASL) associated with tropical storms were first introduced into the meteorological literature in Anthes (1982, p. 69). Sea-spray is generated by wave breaking through mechanisms that can be indirect (when the air trapped below a wave results in bubbles that cause film and jet droplets) or direct (when braking waves produce spume or splash droplets). There is no dispute that under tropicalcyclone winds, sea-spray can become omnipresent and form a transition layer between the air and sea (see, e.g. Black et al. 1986). Numerical experiments using theoretical and weather prediction models indicate that the ratio of enthalpy bulk transfer coefficient to surface drag coefficient must be in the range of $0.75-1.25$ in order for simulated hurricanes to be of realistic intensity (Emanuel 1995; Braun and Tao 2000). However, within the range in which reliable direct flux measurements exist, the observed value of this ratio over the sea is 0.70 at low wind speeds, but decreases significantly below 0.70 with increasing wind speed. One possibility for this discrepancy is the failure of the traditional bulk transfer coefficients to take into account the effect of sea-spray. High winds generate large re-entrant sea-spray droplets that tend to increase the sea-air enthalpy transfer and, thus, have a positive feedback on the intensification of tropical cyclones (Bao et al. 2000; Andreas and Emanuel 2001). On the other hand, sea-spray is generated at the expense of the momentum of the airflow, which in effect causes the direct, air-to-sea turbulent momentum flux to change.

Once sea-spray droplets are generated, their evolution and interaction with the ambient air are governed by the principles of fluid dynamics and thermodynamics. If we assume that the mechanism for sea-spray droplets being suspended in the air is analogous to that for drifting snow, wind-blown sand in deserts, and the transport of sediment over riverbeds or the ocean floor, then there is an extensive body of literature on the first principle-based parametrized relations between the suspended sea-spray mass and the loading atmospheric turbulence (see, e.g. Barenblatt 1996, p. 301; Lykossov 2001). On the other hand, the thermodynamic effect of sea-spray on the air-sea enthalpy transfer is a relatively new subject (see, e.g. Fairall et al. 1994; Andreas and Emanuel 2001). Difficulties in taking into account properly the effects of sea-spray on the air-sea enthalpy transfer are related to the determination of the interaction between the suspended particles and the flow medium. The interaction for sand and sediments is limited to the exchange of momentum; however, the exchange of heat and moisture is involved for snow particles (Bintanja 2000) and sea-spray droplets (Fairall et al. 1994) because of the sublimation/evaporation of snow particles/sea-spray droplets. However, the importance of the effects of sea-spray on the air-sea momentum and heat fluxes in the ASL during tropical storms, and how the effects may be parametrized in weather predictions models still remain a subject of research. The combined feedback effects of sea-spray to the overall air-sea momentum and enthalpy fluxes have been debated since such a combination adds to the complexity of air-sea interaction in general.

Although the impact of feedback effects of sea-spray on air-sea interaction is a complex problem, the operational demand for accurate prediction of tropical storm intensity requires physically sound parametrizations of the sea-spray impact on the air-sea momentum and enthalpy exchange in numerical weather prediction models. There are a few basic questions needing to be answered before such parametrizations can ever be sensibly developed. If the contribution of the spray-mediated fluxes for sensible heat and moisture are not negligible, 
how do these mediated fluxes influence the vertical distribution of temperature and moisture, and the vertical distribution of the direct turbulent fluxes of sensible heat and moisture above breaking waves? What is the impact of the spray-mediated fluxes on the sensible heat and moisture exchange coefficients, and can this impact be measured? It is obvious that field measurements are essential to answer these questions. However, the inimical environment of violent winds and rough seas associated with tropical storms makes direct measurements of sensible and moisture fluxes over the open sea extremely difficult, and only a few reliable measurements have ever been made. Theoretical approaches are absolutely necessary to address these questions. One such approach is the numerical modelling of the atmospheric surface layer above the breaking waves that is based on balance equations of momentum, turbulent kinetic energy and dissipation, sensible heat, and moisture (e.g Makin et al. 1995; Kepert et al. 1999).

In this study, the feedback effects of sea-spray on the mean wind, temperature, and moisture profiles in the atmospheric surface layer associated with tropical cyclones is investigated using a one-dimensional (1-D)-coupled sea-spray and ASL model. The rest of the article is organized as follows: in the next Section, the details of the 1-D model are explained and the numerical experiment design to investigate the individual and combined effects of sea-spray on the momentum and heat fluxes within the atmospheric surface layer are described; Sect. 3 presents the results from the numerical experiments; and discussions and conclusions are provided in Sect. 4.

\section{Model Description and Diagnosis}

\subsection{Surface-Layer Model}

The ASL model used in our study is based on that developed by Kepert and Fairall (1999) and Kepert et al. (1999). In this model, the Mellor-Yamada 1.5-order turbulence closure scheme is used to simulate turbulent mixing; horizontal variations of the model state are neglected. The model is coupled to an explicit sea-spray model that takes into account the effect of saline droplet transport and evaporation. The governing equations of mean horizontal momentum, potential temperature, and specific humidity for the 1-D model, when rotation effects are neglected, are

$$
\begin{array}{r}
\frac{\partial u}{\partial t}=-\frac{\partial}{\partial z}\left(\overline{u^{\prime} w^{\prime}}\right), \\
\frac{\partial \theta}{\partial t}=-\frac{\partial\left(\overline{w^{\prime} \theta^{\prime}}\right)}{\partial z}+\frac{L_{\mathrm{v}}}{\rho c_{\mathrm{p}}} E_{\mathrm{sn}}, \\
\frac{\partial q_{\mathrm{v}}}{\partial t}=-\frac{\partial\left(\overline{w^{\prime} q_{\mathrm{v}}^{\prime}}\right)}{\partial z} .
\end{array}
$$

where the $x$-axis is parallel to the horizontal component of the wind $u, w$ is its vertical component, $\theta$ is the potential temperature, $\rho$ is the total density of the droplet-fluid mixture, $c_{\mathrm{p}}$ is the specific heat at constant pressure, $L_{\mathrm{v}}$ is the latent heat of vaporization for water, $E_{\mathrm{Sn}}$ is the droplet evaporation rate, $q_{\mathrm{v}}$ is the specific humidity, and $z$ is the height. We decomposed the quantities into a sum of a mean and a turbulent part (indicating with the prime the turbulent part of the variables). 
When droplets are ejected into the atmosphere, their temperature adjusts to the wet-bulb temperature in the residence time scale depending on the droplet size, but on the order of tens of microseconds to about a second (Andreas 1995). A larger time scale (about three orders of magnitude larger) is required for the droplets to evaporate and lose a substantial part of their initial mass. When wind speeds exceed $40 \mathrm{~m} \mathrm{~s}^{-1}$, a droplet suspension layer starts to form right above the sea surface, in which turbulence tends to extend the residence time scale of the droplets due to the upward lifting by turbulence against the downward gravitational force. Under hurricane wind speeds, this layer is assumed to be characterized by the regime of limiting saturation, in which the airflow is loaded with the maximum possible amount of droplets for the given friction velocity (see, e.g., Makin 2005).

The solution for a two-phase flow in a regime of limiting saturation relies on the turbulent kinetic energy (TKE) equation (Barenblatt 1979), which has the advantage of not requiring boundary conditions for the droplet concentration. The local tendency of the turbulent kinetic energy (denoted by $q^{2} / 2$ ) depends on the advection of TKE by the mean wind, the buoyant production or consumption term, shear production term, the vertical turbulent transport, the pressure correlation term that describes how TKE is redistributed by pressure perturbations, and viscous dissipation. After various assumptions and approximations associated with the 1-D surface layer model, the governing equation for TKE used in the 2.5-level turbulence closure model introduced in Mellor and Yamada (1982) is

$$
\frac{\partial}{\partial t}\left(\frac{q^{2}}{2}\right)-\frac{\partial}{\partial z}\left[l q K_{\mathrm{q}}\left(\frac{\partial}{\partial z}\right)\left(\frac{q^{2}}{2}\right)\right]=-\overline{u^{\prime} w^{\prime}}\left(\frac{\partial u}{\partial z}\right)+\beta g \overline{w^{\prime} \vartheta_{\mathrm{v}}^{\prime}}-\varepsilon .
$$

where $K_{\mathrm{q}}$ and $\beta$ are the constants determined by experimental data and internal relations, respectively, as explained in Mellor and Yamada (1982), $g$ is the gravitational acceleration, and $\vartheta_{\mathrm{v}}^{\prime}$ is the turbulent part of the virtual potential temperature $\vartheta_{\mathrm{v}}$. The first and second terms on the right-hand side of the equation describe the production of TKE due to shear and buoyancy, $K_{\mathrm{q}}$ is the virtual potential temperature, $\varepsilon$ is the dissipation term $\left(\varepsilon=\frac{q^{3}}{B_{1} l}, B_{1}\right.$ is a constant as introduced in Mellor and Yamada (1982), and $l$ is the master length scale). Following the first-order closure assumption, the flux terms $\overline{u^{\prime} w^{\prime}}$ and $\overline{w^{\prime} \vartheta_{\mathrm{v}}^{\prime}}$ in Eq. 2 can be expressed as

$$
\begin{gathered}
\overline{u^{\prime} w^{\prime}}=-K_{\mathrm{M}} \frac{\partial u}{\partial z}, \\
\overline{w^{\prime} \vartheta_{\mathrm{v}}^{\prime}}=-K_{\mathrm{H}} \frac{\partial \vartheta_{\mathrm{v}}}{\partial z},
\end{gathered}
$$

where the exchanges coefficients $K_{\mathrm{M}}$ and $K_{\mathrm{H}}$ are determined from the Mellor-Yamada level2.5 turbulent closure schemes, which can be written as

$$
\begin{gathered}
K_{\mathrm{M}}=l q S_{\mathrm{M}}, \\
K_{\mathrm{H}}=l q S_{\mathrm{H}} .
\end{gathered}
$$

Relations for stability functions $S_{\mathrm{M}}$ and $S_{\mathrm{H}}$ (Mellor and Yamada 1982) are given through the following two simultaneous equations:

$$
\begin{array}{r}
S_{\mathrm{M}}\left(6 A_{1} A_{2} G_{\mathrm{M}}\right)+S_{\mathrm{H}}\left(1-3 A_{2} B_{2} G_{\mathrm{H}}-12 A_{1} A_{2} G_{\mathrm{H}}\right)=A_{2}, \\
S_{\mathrm{M}}\left(1+6 A_{1}^{2} G_{\mathrm{M}}-9 A_{1} A_{2} G_{\mathrm{H}}\right)-S_{\mathrm{H}}\left(12 A_{1}^{2} G_{\mathrm{H}}+9 A_{1} A_{2} G_{\mathrm{H}}\right)=A_{1}\left(1-3 C_{1}\right) .
\end{array}
$$

where again $A_{1}, A_{2}, B_{2}$, and $C_{1}$ are constants determined by experimental data and internal relations as explained in Mellor and Yamada (1982), while $G_{\mathrm{M}}$ and $G_{\mathrm{H}}$ are determined from the relations: 


$$
\begin{gathered}
G_{\mathrm{M}}=\left(\frac{l^{2}}{q^{2}}\right)\left(\frac{\partial u}{\partial z}\right)^{2}, \\
G_{\mathrm{H}}=-\left(\frac{l^{2}}{q^{2}}\right) \beta g \frac{\partial \vartheta_{\mathrm{v}}}{\partial z} .
\end{gathered}
$$

From the previous equations, the contribution of the TKE production and dissipation terms can be rewritten in the form:

$$
-\overline{u^{\prime} w^{\prime}}\left(\frac{\partial u}{\partial z}\right)+\beta g \overline{w^{\prime} \vartheta_{\mathrm{v}}^{\prime}}-\varepsilon=\left[S_{\mathrm{M}} G_{\mathrm{M}}+S_{\mathrm{H}} G_{\mathrm{H}}-\frac{1}{B_{1}}\right] \frac{q^{3}}{l} .
$$

\subsection{Explicit Sea-Spray Model}

The Eulerian, explicit sea-spray droplet model introduced by Kepert and Fairall (1999) and Kepert et al. (1999) is coupled with the ASL model in order to understand the essential physics that should be taken into account in a parametrization scheme of sea-spray effects on the surface heat and momentum fluxes. A number of explicit sea-spray models have been developed to investigate the effect of droplets on air-sea interaction. Some of them use a Lagrangian approach, running the model a significant number of times to determine a statistically valid number of droplet trajectories that need to be averaged in order to provide vertical profiles of fluxes. The disadvantage of such models is that it is difficult to determine the feedback effect generated by the presence of droplets. Eulerian models overcome the Lagrangian weakness by using droplet concentration as a function of height and radius and using the transport and evaporation equations to determine the flux of droplets.

In this explicit sea-spray model, the droplet population is split into $N(N=16)$ size bins categories of radius $r_{n}(n=1,2, \ldots, 16)$, each of which is defined by the nominal radius, varying from the droplets initial radius, down to $7 / 16$ of it. Thirty-six levels are spaced logarithmically near the surface, with a bottom model level at $3 \mathrm{~m}$ above the sea surface. The spacing of the vertical model levels becomes linear near the top level (close to $6.5 \mathrm{~km}$ ). For the initial conditions, different values of $10-\mathrm{m}$ wind speed with corresponding potential temperature set to $298.9 \mathrm{~K}$ were used for different simulations, and the sea surface temperature was set to $300 \mathrm{~K}$. The mean vertical velocity of wind (horizontal divergence) is set equal to zero. In all the simulations, droplets are assumed to be generated and ejected into the air at $7 \mathrm{~m}$ above mean sea level (typical wave height in a tropical cyclone). Admittedly, setting the ejection level at $7 \mathrm{~m}$ is rather artificial. However, the qualitative aspects of the results would not be expected to change if the ejection level were set to a different elevation above the mean sea level (e.g., $25 \mathrm{~m}$ ), particularly regarding the physics of the impact of droplet mass loading on the momentum and enthalpy fluxes above the ejection level since all the runs are performed and compared at the same ejection level. The details of the generation due to wave breaking and the thermodynamics of spray droplets are given in the next subsections.

\subsubsection{Source Function}

To quantify the effect of sea-spray on air-sea exchange processes requires information on the production rate of droplets at various radii as a function of the wind speed or wave states. In this study, this information is provided through the droplet source function based on the physical model of droplet generation developed by Fairall et al. (2009, Eq. B9). This physical 

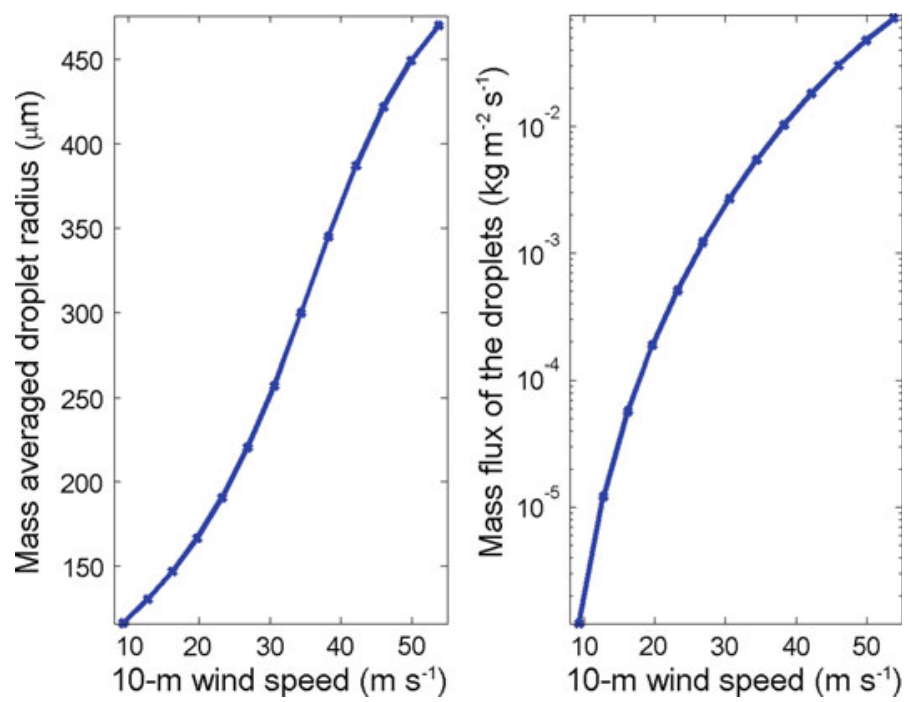

Fig. 1 Left Mass-averaged droplet radius as a function of the 10-m wind speed. Right Mass flux of the droplets as a function of the $10-\mathrm{m}$ wind speed

model incorporates the most recent laboratory measurements and current understanding of the turbulence energetics in wave breaking. It predicts the size spectrum of sea-spray droplets produced by the ocean as a function of the forcing, wind speed, surface stress, and wave properties (if available). The mass-averaged droplet radius can be plotted as a function of the 10-m wind speed, and the same can be done for the mass flux of the droplets as in Fig. 1.

\subsubsection{Droplet Evaporation}

The computation of droplet evaporation is critical in explicit droplet modelling and is not trivial. According to Andreas (1989), the droplet equilibrium temperature and evaporation rate can be calculated using salinity-modified cloud microphysics equations, including a ventilation factor (Fairall et al. 1994). Considering that the time scale for droplet temperature adjustments is much less than radius adjustments, it is assumed in this modelling study that the droplet instantaneously reaches the temperature $T_{\mathrm{ev}}$, computed as in Kepert (1996) from

$$
\begin{aligned}
& {\left[\frac{\gamma}{T_{\mathrm{a}}^{2}}\left(\frac{\alpha^{2}}{2}-2 \alpha+1\right) \exp (y)\right](\Delta T)^{2}+\left[1+\frac{\gamma}{T_{\mathrm{a}}}(\alpha-1) \exp (y)\right](\Delta T)} \\
& -\gamma\left(h_{\mathrm{f}}-\exp (y)\right)=0
\end{aligned}
$$

where $\Delta T=T_{\mathrm{ev}}-T_{\mathrm{a}}\left(T_{\mathrm{a}}\right.$ is the air temperature), $\gamma=\frac{e_{\mathrm{sat}}\left(T_{\mathrm{a}}\right)}{T_{\mathrm{a}}} \frac{L_{\mathrm{v}} M_{\mathrm{w}} D_{\mathrm{w}}^{\prime}}{R k_{\mathrm{a}}^{\prime}}, e_{\mathrm{sat}}$ is the saturation vapour pressure of pure water, $L_{\mathrm{v}}$ is the latent heat of vaporization for water, $D_{\mathrm{w}}^{\prime}$ and $k_{\mathrm{a}}^{\prime}$ are the molecular diffusivities in air of water and heat, respectively, $R$ is the universal gas constant, $\alpha=\frac{M_{\mathrm{w}} L_{\mathrm{v}}}{R T_{\mathrm{a}}}$, and $h_{\mathrm{f}}$ is the fractional relative humidity. The expression for $y$ is

$$
y\left(T_{\mathrm{ev}}, r_{n}, s\right)=\frac{2 M_{\mathrm{w}} \varsigma_{\mathrm{s}}}{R T_{\mathrm{ev}} \rho_{\mathrm{w}} r_{n}}-\frac{v \Phi_{\mathrm{s}}(s) m_{\mathrm{S}}\left(M_{\mathrm{w}} / M_{\mathrm{s}}\right)}{\left(4 \pi r_{n}^{3} \rho_{n} / 3\right)-m_{\mathrm{s}}},
$$

in which $r_{n}$ is the droplet radius, $s$ is the salinity, $M_{\mathrm{w}}$ and $M_{\mathrm{S}}$ are the molecular weights of water and salt, respectively, $m_{\mathrm{s}}$ is the mass of salt in the droplet, $\varsigma_{\mathrm{s}}$ is the surface tension of a 
plain water surface of salinity $s, \rho_{\mathrm{w}}$, and $\rho_{n}$ are the density of pure water and droplet, respectively, $v$ is the number of ions into which sodium chloride dissociates, $\Phi_{\mathrm{s}}$ is the practical osmotic coefficient of sodium chloride dissolved in water. The previous equation is solved for $\Delta T$, and therefore $T_{\mathrm{ev}}$ is computed as a function of droplet radius and salinity.

\subsubsection{Thermal Feedback on Mean Flow}

Once ejected into the air, spray droplets increase the effective area of the air-water interface. The release of sensible heat and the evaporation from the spray droplets enhance the enthalpy exchange between the sea and the air. Also, the increased density of the air-droplet mixture and the enthalpy fluxes associated with the spray droplets change the thermal stratification of the surface layer. Properly simulating these processes requires the specification of the sensible and latent heat fluxes from the spray droplets into the air. In this study, the droplet-mediated heat fluxes are added to the equation of the liquid water equivalent potential temperature $\vartheta_{1}$ as follows:

$$
\frac{\partial \vartheta_{1}}{\partial t}=-w \frac{\partial \vartheta_{1}}{\partial z}+\frac{\partial}{\partial z}\left(K_{\mathrm{H}} \frac{\partial \vartheta_{1}}{\partial z}\right)+\frac{\dot{q}_{\mathrm{s}}-\dot{q}_{1}^{*}}{\rho_{\mathrm{a}} c_{\mathrm{p}}},
$$

where $\rho_{\mathrm{a}}$ is the density of air, $w$ is the mean vertical velocity, $\dot{q}_{\mathrm{s}}$ is the sensible heat flux from the spray droplets to the air, and $\dot{q}_{1}^{*}$ is the heat supplied by the air for the evaporation of spray droplets, and the other variables have the same meanings as specified above in the text. Essentially, the evaporation of sea-spray affects the ambient air though the term $\left(\dot{q}_{\mathrm{s}}-\dot{q}_{1}^{*}\right)$ in Eq. 10.

Originally, in Kepert and Fairall (1999) and Kepert et al. (1999), $\dot{q}_{1}^{*}$ is specified as the latent heat input rate per unit volume from the spray droplets (see more details below), while $\dot{q}_{\mathrm{s}}$, defined as the latent heat input rate per unit volume from the spray droplets, is formulated as

$$
\left\{\begin{array}{ll}
\dot{q}_{\mathrm{s}}=\dot{q}_{\mathrm{s}}(z, t)=\int c_{\mathrm{p}} \rho_{\mathrm{w}} \frac{4}{3} \pi r^{3}\left(T_{\mathrm{s}}-T_{\mathrm{h}}\right) S(r) \mathrm{d} r & \text { at } z=h \\
\dot{q}_{\mathrm{s}}=\dot{q}_{\mathrm{s}}(z, t)=0 & \text { elsewhere }
\end{array},\right.
$$

where $T_{\mathrm{h}}$ is the air temperature at the droplets ejection height $h$, and $S(r)$ is the generation rate of spray droplets of radius $r$. It is assumed in this formulation that

(1) the spray droplets release the sensible heat instantaneously on their formation; and

(2) all the heat required for spray evaporation is supplied by the ambient air.

The formulation for the latent heat flux from the spray droplets takes the exact form as in Kepert et al. (1999):

$$
\dot{q}_{1}^{*}=\int L_{\mathrm{v}} \rho_{\mathrm{w}} 4 \pi r^{2} \frac{\partial r}{\partial t} n(r) \mathrm{d} r .
$$

This formulation requires an equation for $\frac{\partial r}{\partial t}$, which is written as

$$
r \frac{\partial r}{\partial t}=\frac{f-\exp (y)}{\frac{\rho_{\mathrm{d}} R T}{D_{\mathrm{w}}^{\prime} M_{\mathrm{w}} e_{\mathrm{sat}}(T)}+\frac{L_{\mathrm{v}} \rho_{\mathrm{d}}}{T k_{\mathrm{a}^{\prime}}}\left(\frac{L_{\mathrm{v}} M_{\mathrm{w}}}{R T}-1\right)},
$$

where all the symbols are defined in Sect. 2.2.2.

Following the principles governing saline droplet evaluation, Andreas (1990) shows that, under a wide range of physically reasonable conditions, the droplet reaches an equilibrium temperature long before it reaches the equilibrium radius. This equilibrium temperature is 
very close to the wet-bulb temperature for the droplet, taking into account the effects of curvature and salinity. After this initial adjustment, due to continuing evaporation, the droplet temperature will follow the evolution of the wet-bulb temperature and undergo a relatively slow change in response to the varying droplet salinity. Andreas and Emanuel (2001) further show that after a spray droplet is formed, less than $1 \%$ of its mass needs to evaporate to drop its temperature to the wet-bulb temperature and, more importantly, the heat required for this evaporation can be sufficiently balanced by the sensible heat loss of the droplet. All these results indicate that the heat required for the initial evaporation of droplets immediately after their formation is mainly from the droplets. The heat supplied by the ambient air for the evaporation of the droplets becomes significant only after the droplets reach their wet-bulb temperature, and the actual amount of the heat supplied by the ambient air increases with the droplets' residence time in the air.

The above-mentioned results strongly indicate that while it is reasonable to assume that the spray droplets release the sensible heat instantaneously on their formation, it is questionable to assume that all the heat required for spray evaporation is supplied by the ambient air, especially for large, re-entrant spray droplets. To take into consideration that droplets carry sensible heat for their initial evaporation, we propose to formulate $\dot{q}_{\mathrm{s}}$ as:

$$
\left\{\begin{array}{ll}
\dot{q}_{\mathrm{s}}=\dot{q}_{\mathrm{s}}(z, t)=\int c_{\mathrm{p}} \rho_{\mathrm{w}} \frac{4}{3} \pi r^{3}\left(T_{\mathrm{s}}-T_{\mathrm{ev}}\right) S(r) \mathrm{d} r & \text { at } z=h \\
\dot{q}_{\mathrm{s}}=\dot{q}_{\mathrm{s}}(z, t)=0 & \text { elsewhere }
\end{array},\right.
$$

where $T_{\mathrm{ev}}$ is the initial wet-bulb temperature for the droplet at the ejection height. In Sect. 3, comparisons will be made to the states of the ASL from the simulations using the original (Eq. 11) or modified (Eq. 14) formulations of the sensible heat flux from droplets.

In summary, the modified formulation of $\dot{q}_{\mathrm{s}}$ treats the initial cooling of droplets from $T_{\mathrm{S}}$ to $T_{\mathrm{ev}}$ as a two-step process. First, the droplets release sensible heat to the ambient air of temperature $T_{\mathrm{h}}$, and thus the droplets cool down from $T_{\mathrm{S}}$ to $T_{\mathrm{h}}$. Second, the droplets further cool down from $T_{\mathrm{h}}$ to the wet-bulb temperature, $T_{\mathrm{ev}}$, by evaporation. The initial cooling of the droplets from $T_{\mathrm{s}}$ to $T_{\mathrm{ev}}$ in the model can be assumed to occur very fast and only at the elevation where they are ejected into the air. This assumption is consistent with the results from the explicit numerical simulations of droplet microphysics by Andreas (1990). Consistently, the time scale for the initial cooling to occur is assumed to be smaller than one time step in the model. After the initial cooling, if these droplets stay suspended in the air, evaporation of the droplets continues at the expense of the sensible heat from the ambient air. Thus, for small droplets that tend to evaporate entirely, $\dot{q}_{\mathrm{s}}$ is smaller than $\dot{q}_{1}^{*}$, and the air is cooled down. For large droplets that do not have enough time to evaporate much before falling back to the sea, $\dot{q}_{\mathrm{s}}$ is greater than $\dot{q}_{1}^{*}$, and there is a net increase of enthalpy by sea-spray. It can be seen that for large droplets $(r \approx 360 \mu \mathrm{m})$, the modified formulation significantly reduces the cooling effect of the previous formulation in the droplet evaporation layer.

\subsubsection{Prognostic Equation of Sea-Spray Droplet Mass}

Denoting the droplet mass concentration with $\eta$, the budget equation for the suspended seaspray droplets mass can be written as

$$
\frac{\partial \eta}{\partial t}=-V_{\mathrm{f}} \frac{\partial \eta}{\partial z}+\frac{\partial}{\partial z}\left(K_{\mathrm{D}} \frac{\partial \eta}{\partial z}\right)-\frac{\partial}{\partial r}\left(\frac{\partial r}{\partial t} \eta\right)+S_{n},
$$

where $V_{\mathrm{f}}$ is the final fall velocity, $K_{\mathrm{D}}$ is the turbulent diffusion coefficient for droplets, $S_{n}$ is the net source term, and the other symbols have the same meaning as introduced before. The four terms on the right-hand side represent, respectively, the downward flux of suspended 
droplets due to gravity, vertical transport by turbulent diffusion, transfer to a different size by evaporation, and production. The value of $K_{\mathrm{D}}$ is computed as in Rouault et al. (1991):

$$
K_{\mathrm{D}}=\frac{K_{\mathrm{H}}}{1+C_{2}\left(V_{\mathrm{f}}^{2} / \overline{w^{\prime 2}}\right)},
$$

where $C_{2}$ is a constant to be adjusted by comparison with experimental data (set equal to 2 in the model input file) and $\overline{w^{\prime 2}}$ is the vertical velocity variance. According to Eq. (73) of Rouault et al. (1991), the model assumes the constant flux layer parametrization $\overline{w^{\prime 2}}=1.56 u_{*}^{2}$, where $u_{*}$ is the friction velocity.

\section{Results and Discussion}

This section is dedicated to the comparisons of results from various simulations for the purpose of demonstrating qualitatively how spray droplets affect the atmospheric surface layer. As mentioned before, in all the simulations, spray droplets are assumed to be ejected into the air at a height of $7 \mathrm{~m}$ above the mean sea level, and the bottom model level is set at $3 \mathrm{~m}$. According to the droplet source function introduced in Sect. 2.2.1, we can determine a reasonable value for the droplet radius and mass droplet as a function of the 10-m wind speed. We choose to run the 1-D model with the initialization values shown in Table 1. In this table, $E_{\mathrm{p}}$ is the potential evaporation for the droplets (Fairall et al. 1994); i.e. the total heat flux that would result if all spray droplets would evaporate in the atmosphere and convert to water vapour before impacting the ocean. It can be expressed as

$$
E_{\mathrm{p}}=L_{\mathrm{v}} F_{\mathrm{m}}
$$

where $F_{\mathrm{m}}=\frac{4 \pi}{3} \rho_{\mathrm{w}} r^{3} S_{n}$ is the mass flux. With the loading of spray droplets, variables in the ASL will be modified. The degree of the modification depends on how the thermal feedback is taken into account.

A total of six simulation experiments is conducted. The differences among the experiments are summarized in Table 2. Following Andreas and Emanuel (2001) and Gall et al. (2008), to take into consideration the modifications on the momentum at the height where the spray is ejected, we apply a simple momentum parametrization based on the conservation of momentum of the mean wind. A new value of the wind velocity was then recomputed for this level. It was assumed that sea-spray only has a direct impact at the height where the spray is ejected, with the higher levels modified through vertical turbulent diffusion of momentum.

Table 1 Values for 10-m wind speed, droplet radius, mass of the droplets, and potential evaporation used for run the model

\begin{tabular}{lllr}
\hline $10-\mathrm{m}_{\text {wind speed }\left(\mathrm{m} \mathrm{s}^{-1}\right)}$ & Droplet radius $(\mu \mathrm{m})$ & Mass flux of the droplets $\left(\mathrm{kg} \mathrm{m}^{-2} \mathrm{~s}^{-1}\right)$ & $E_{\mathrm{p}}\left(\mathrm{W} \mathrm{m}^{-2}\right)$ \\
\hline 25 & 200 & 0.0008 & 2,100 \\
30 & 256 & 0.0024 & 6,000 \\
40 & 360 & 0.0120 & 30,000 \\
50 & 450 & 0.0480 & 120,000 \\
60 & 500 & 0.0800 & 200,000 \\
\hline
\end{tabular}


Table 2 Summary of six experiments presented in Sect. 3

\begin{tabular}{ll}
\hline Experiment No. & Experiment description \\
\hline 1 & $\begin{array}{l}\text { No sea-spray } \\
\text { Sea-spray with the thermal feedback term as originally used in the 1-D } \\
\text { model (Eq. 11) } \\
\text { Sea-spray with the thermal feedback term modified according to Eq. } 14 \\
\text { Sea-spray with the thermal feedback term as originally used in the 1-D } \\
\text { model but modifications on the momentum at the height where the spray } \\
\text { is ejected }\end{array}$ \\
$\begin{array}{l}\text { Sea-spray with the thermal feedback term modified according to Eq. 14, but } \\
\text { modifications on the momentum at the height where the spray is ejected } \\
5\end{array}$ & $\begin{array}{l}\text { Sea-spray with the thermal effect turned off, but leaving the modifications } \\
\text { on the momentum at the height where the spray is ejected }\end{array}$ \\
\hline
\end{tabular}

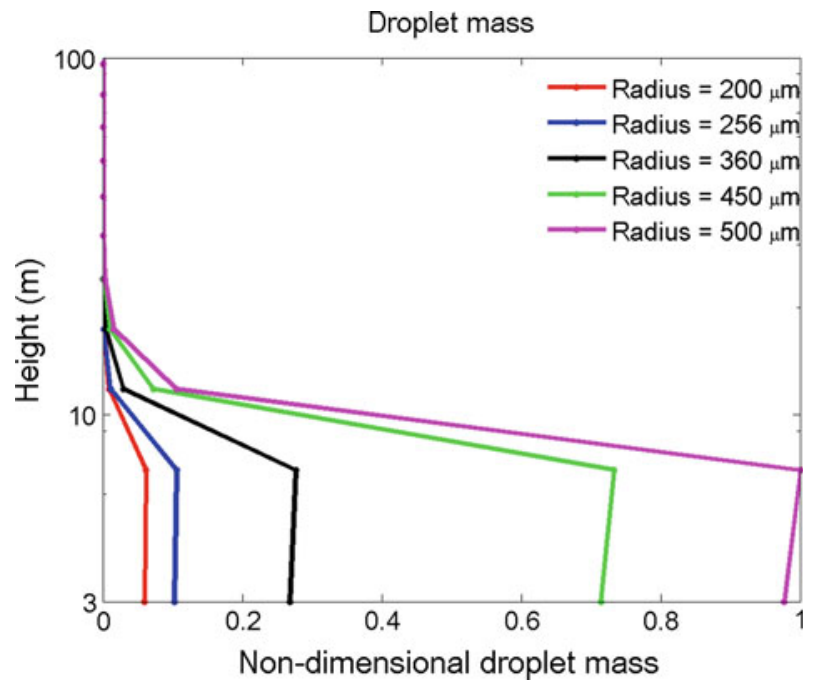

Fig. 2 Vertical profiles of total droplet mass at $24 \mathrm{~h}$ into the simulation (i.e., $22 \mathrm{~h}$ after the generation of spray is turned on) for $10-\mathrm{m}$ wind speed: $\mathbf{a} 25 \mathrm{~m} \mathrm{~s}^{-1} ; \mathbf{b} 30 \mathrm{~ms}^{-1} ; \mathbf{c} 40 \mathrm{~ms}^{-1} ; \mathbf{d ~} 50 \mathrm{~m} \mathrm{~s}^{-1}$; and e $60 \mathrm{~m} \mathrm{~s}^{-1}$

Identical initial potential temperature and relative humidity profiles are used, along with the sea-surface temperature of $300 \mathrm{~K}$ in all the experiments. The initial wind profile, however, is prescribed to yield 10-m wind speeds corresponding to the values listed in Table 1 at $2 \mathrm{~h}$ after the model simulation in each of the six experiments. To simplify the comparisons of the results from the experiments, spray droplets are set to be ejected into the air at $7 \mathrm{~m}$ above the mean sea level at $2 \mathrm{~h}$ into the simulation in all the experiments, and then the model is allowed to continue to run for $22 \mathrm{~h}$. This is to make sure that all the results correspond to the regime of limiting saturation in the droplet-laden atmospheric surface layer. Figure 2 shows the vertical profiles of total droplet mass at $24 \mathrm{~h}$ into the simulation (i.e. $22 \mathrm{~h}$ after the generation of spray is turned on). It is interesting to note that these profiles are self-similar, a result that is consistent with the finding in the theoretical study carried out by Lykossov (2001). The dependence of the total droplet mass on elevation $z$ is also very similar to that revealed by Kepert et al. (1999). 
In the rest of this section, the profiles of wind-speed change, air temperature, and heat and momentum fluxes in the lowest $100 \mathrm{~m}$ of the atmospheric surface layer, which is most relevant to the air-sea enthalpy and momentum exchange, will be compared for all the different 10-m wind speeds introduced in Table 1. Also, the impact of spray droplets on the surface drag coefficient and the surface layer stability will be diagnosed.

\subsection{Wind and Temperature Profiles}

Since it is assumed that in all the simulations the surface is warmer than the air above, the wind-speed profiles deviate from the neutral (in the absence of spray) profile and resemble a typical unstable profile (not shown) as the initial wind speed increases. The profiles of windspeed changes relative to the control simulation without spray (Exp. 1) are depicted in Fig. 3 to illustrate how the winds in the atmospheric surface layer are influenced by droplet loading. When the 10 -m wind speed is $25 \mathrm{~m} \mathrm{~s}^{-1}$ or lower, the impact of droplet loading on the wind speed is small enough to be neglected (the wind-speed curves lay over-imposed). When the $10-\mathrm{m}$ wind speed reaches $30 \mathrm{~m} \mathrm{~s}^{-1}$ or higher, the average size of the droplets becomes great enough (above $256 \mu \mathrm{m}$ ) to enhance the vertical mixing and bring down more momentum from levels above to increase the wind speed above the droplet-ejection level. As the $10-\mathrm{m}$ wind speed becomes greater than $30 \mathrm{~m} \mathrm{~s}^{-1}$, the changes in wind speed above the droplet-ejection level are positive, indicating that the thermal effect is to enhance the mixing above the droplet-ejection level. It is interesting to note that the original thermal feedback assumption results in less mixing than the modified one. Also, since the stability enhancement due to droplet loading suppresses turbulence, the combination of both the thermal and momentum effects leads to less mixing (therefore less wind increase) than the thermal effect alone.

Figure 4 shows how vertical profiles of potential temperature $\theta$ are influenced by the presence of the spray generated at various $10-\mathrm{m}$ wind speeds. It indicates significant differences between the original thermal feedback assumption in the 1-D model and the one modified according to Eq. 14 and considerations discussed in Sect. 2.2.3. In fact, the modified thermal feedback assumption produces results opposite to the original one. Particularly, when the modified thermal feedback assumption is used with large droplet radius $(r \approx 360 \mu \mathrm{m}$ or greater) corresponding to the $10-\mathrm{m}$ wind speed of $40 \mathrm{~m} \mathrm{~s}^{-1}$ or greater, the effect of the spray on the air temperature is not to cool it down, but to warm it up (black and green line in panels c-e of Fig. 4). The explanation for the big difference in this case is that the large droplets do not have as much time as the smaller droplets to stay in the air. Therefore, most of the heat required for the evaporation of the larger droplets after their formation is provided by the droplets and not by the ambient air. Also it is shown in Fig. 4 is that the inclusion of the momentum feedback of sea-spray tends is not to influence the thermal effect (black and green lines).

\subsection{Sensible and Latent Heat Fluxes}

Droplet loading affects wind profiles in the ASL through the heat and momentum fluxes. Figure 5 presents profiles of sensible and latent heat fluxes associated with various feedback assumptions corresponding to different 10 -m wind speeds. First, the results from this study confirms those of Kepert et al. (1999) that vertical profiles of sensible and latent heat fluxes are constant with height in the lowest $100 \mathrm{~m}$ when there is no spray (red lines). When spray is ejected into the air and thermal feedback is considered, the heat fluxes are independent of height only above the droplet-eject level (i.e., $7 \mathrm{~m}$ ) for all the $10-\mathrm{m}$ wind speeds. 
Fig. 3 Left Vertical profiles of mean wind speed. Right

Corresponding differences with the case with no sea-spray associated with various feedback effects of sea-spray for a 10-m wind speed $=25 \mathrm{~ms}^{-1}$, droplet radius $=200 \mu \mathrm{m}$, mass of the droplets $=8.4 \times$ $10^{-4} \mathrm{~kg} \mathrm{~m}^{-2} \mathrm{~s}^{-1}$, and potential evaporation $E_{\mathrm{p}}=2,100$ $\left(\mathrm{W} \mathrm{m}^{-2}\right)$; b 10-m wind speed $=$ $30 \mathrm{~m} \mathrm{~s}^{-1}$, droplet radius $=$ $256 \mu \mathrm{m}$, mass of the droplets $=$ $2.4 \times 10^{-3} \mathrm{~kg} \mathrm{~m}^{-2} \mathrm{~s}^{-1}$, and potential evaporation $E_{\mathrm{p}}=6,000$ $\left(\mathrm{W} \mathrm{m}^{-2}\right)$; $\mathbf{c} 10-\mathrm{m}$ wind speed $=$ $40 \mathrm{~m} \mathrm{~s}^{-1}$, droplet radius $=$ $360 \mu \mathrm{m}$, mass of the droplets $=$ $1.2 \times 10^{-2} \mathrm{~kg} \mathrm{~m}^{-2} \mathrm{~s}^{-1}$, and potential evaporation $E_{\mathrm{p}}=$ 30,000 $\left(\mathrm{W} \mathrm{m}^{-2}\right)$; d 10-m wind speed $=50 \mathrm{~m} \mathrm{~s}^{-1}$, droplet radius $=450 \mu \mathrm{m}$, mass of the droplets $=4.8 \times 10^{-2} \mathrm{~kg} \mathrm{~m}^{-2} \mathrm{~s}^{-1}$, potential evaporation $E_{\mathrm{p}}=$ $120,000\left(\mathrm{~W} \mathrm{~m}^{-2}\right)$; and e $10-\mathrm{m}$ wind speed $=60 \mathrm{~m} \mathrm{~s}^{-1}$, droplet radius $=500 \mu \mathrm{m}$, mass of the droplets $=8 \times 10^{-2} \mathrm{~kg} \mathrm{~m}^{-2} \mathrm{~s}^{-1}$, and potential evaporation $E_{\mathrm{p}}=$ $200,000\left(\mathrm{~W} \mathrm{~m}^{-2}\right)$. Some curves cannot be identified because the values are very close
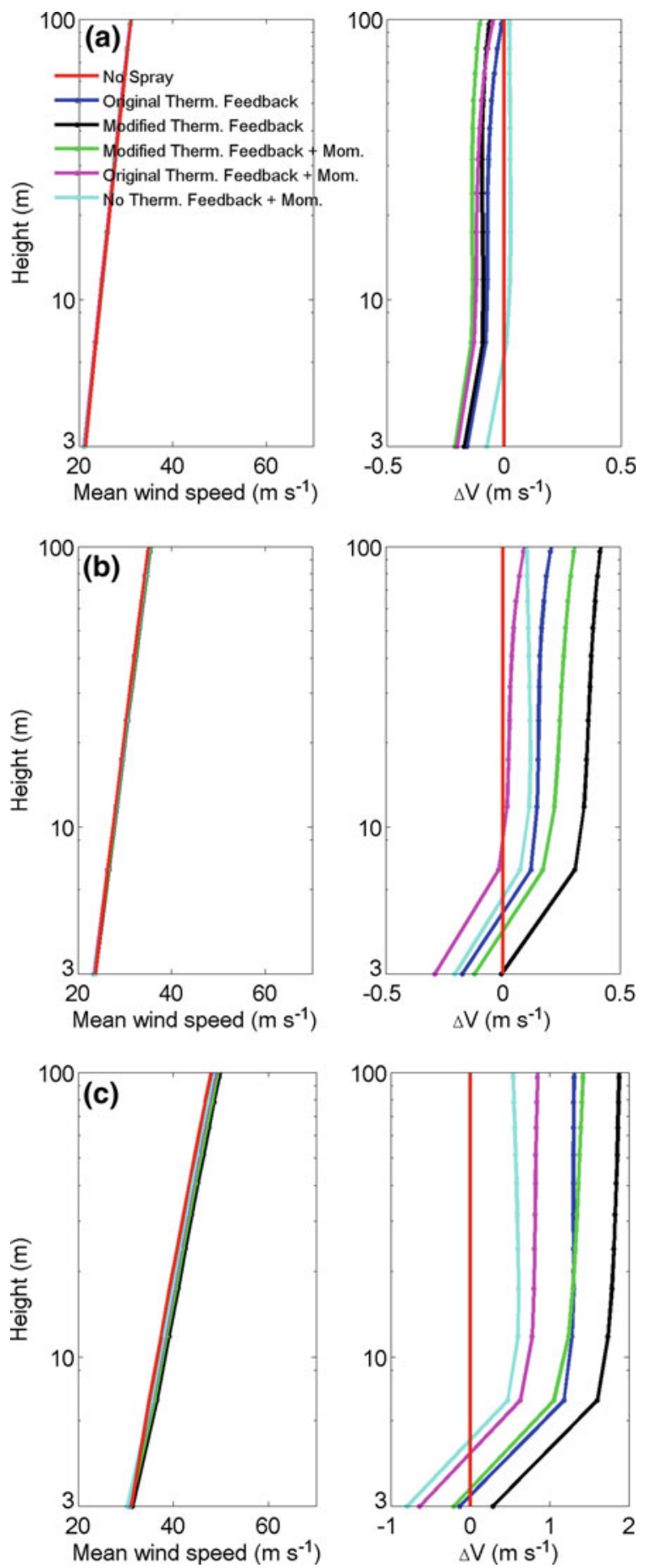
Fig. 3 continued
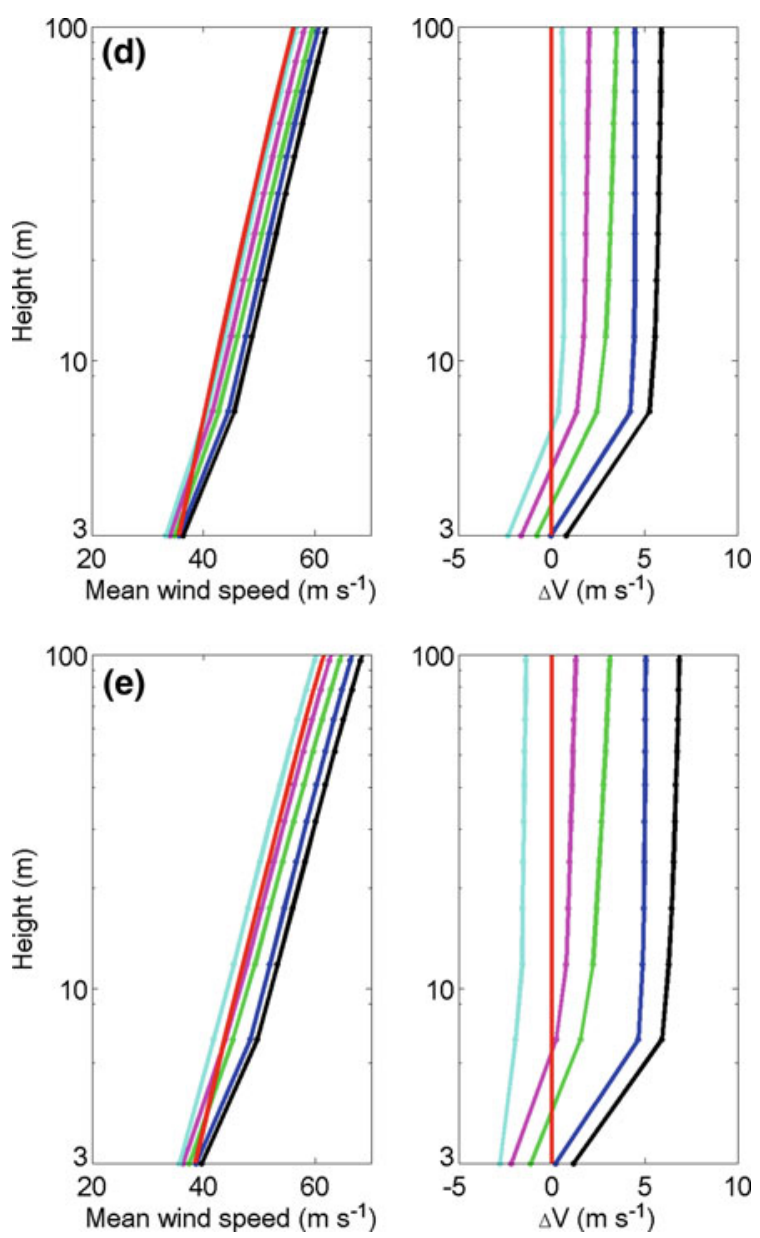

Second, although the evaporation of spray droplets enhance the upward moisture flux, the impact of the droplets on the upward sensible heat flux shows significant differences above the droplet-ejection level between the original thermal feedback assumption and the modified thermal feedback assumption: The former leads to a decrease in the sensible heat flux, while the latter results in an increase in the sensible heat flux at 10-m wind speeds greater than $30 \mathrm{~m} \mathrm{~s}^{-1}$. Further, the heat fluxes are almost constant above the droplet-eject level, strongly suggesting that the Monin-Obukhov similarity relations (Monin and Obukov 1954) should only be valid in the surface layer above the highest elevation where wave breaking takes places.

\subsection{Momentum Flux}

Figure 6 presents the vertical profiles of momentum fluxes associated with various feedback assumptions corresponding to different 10 -m wind speeds. It is seen that the impact of spray droplets on momentum flux increases with droplet size (and thus with 10-m wind speed). As the droplet size increases (Fig. 6b-e), the impact of spray droplets on the momentum flux 

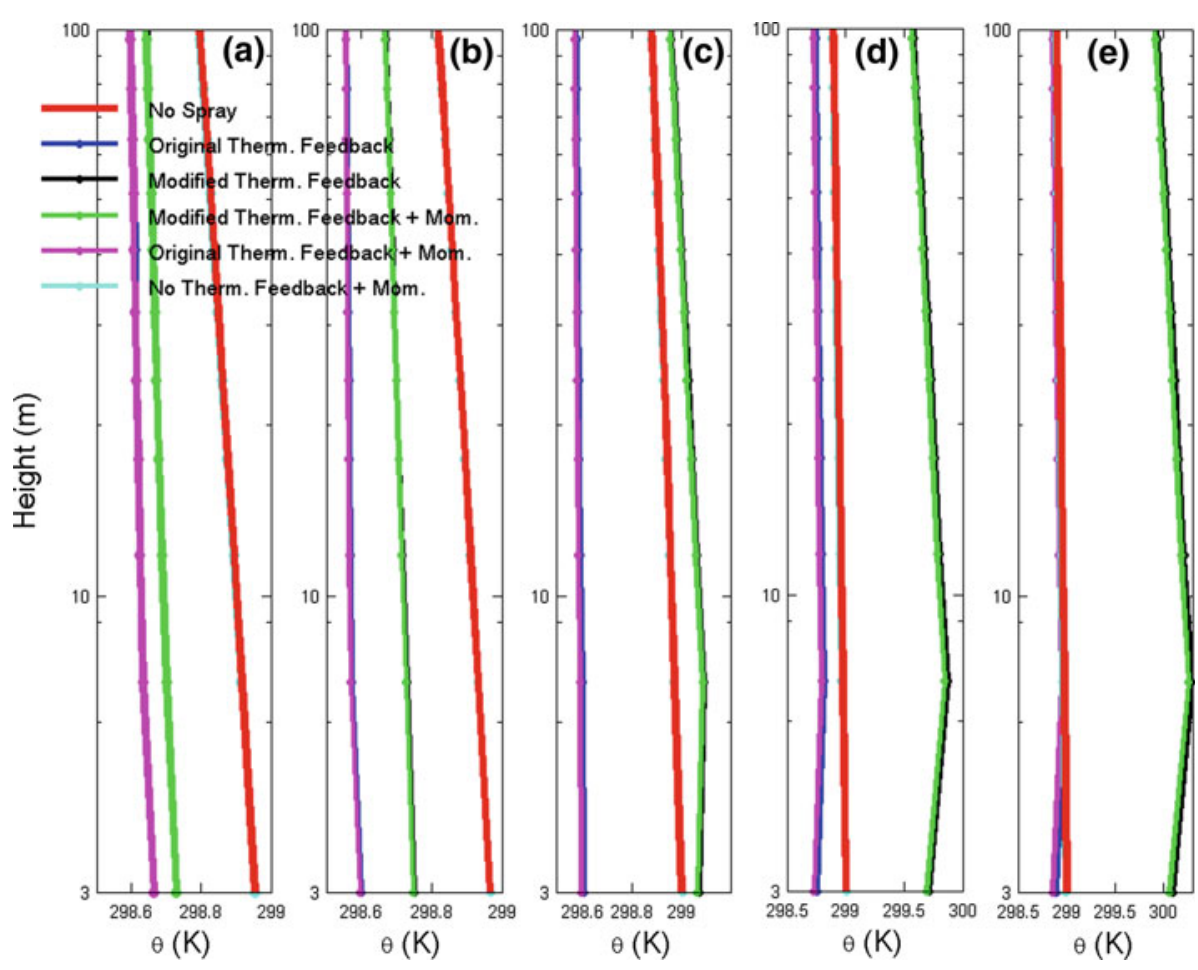

Fig. 4 Vertical profiles of potential temperature associated with various feedback effects of sea-spray for a $10-\mathrm{m}$ wind speed $=25 \mathrm{~m} \mathrm{~s}^{-1}$, droplet radius $=200 \mu \mathrm{m}$, mass of the droplets $=8.4 \times 10^{-4} \mathrm{~kg} \mathrm{~m}^{-2} \mathrm{~s}^{-1}$, and potential evaporation $E_{\mathrm{p}}=2,100\left(\mathrm{~W} \mathrm{~m}^{-2}\right) ; \mathbf{b} 10-\mathrm{m}$ wind speed $=30 \mathrm{~m} \mathrm{~s}^{-1}$, droplet radius $=256 \mu \mathrm{m}$, mass of the droplets $=2.4 \times 10^{-2} \mathrm{~kg} \mathrm{~m}^{-2} \mathrm{~s}^{-1}$, and potential evaporation $E_{\mathrm{p}}=6,000\left(\mathrm{~W} \mathrm{~m}^{-2}\right)$; $\mathbf{c} 10-\mathrm{m}$ wind speed $=40 \mathrm{~m} \mathrm{~s}^{-1}$, droplet radius $=360 \mu \mathrm{m}$, mass of the droplets $=1.2 \times 10^{-2} \mathrm{~kg} \mathrm{~m}^{-2} \mathrm{~s}^{-1}$, and potential evaporation $E_{\mathrm{p}}=30,000\left(\mathrm{~W} \mathrm{~m}^{-2}\right) ; \mathbf{d} 10-\mathrm{m}$ wind speed $=50 \mathrm{~m} \mathrm{~s}^{-1}$, droplet radius $=450 \mu \mathrm{m}$, mass of the droplets $=4.8 \times 10^{-2} \mathrm{~kg} \mathrm{~m}^{-2} \mathrm{~s}^{-1}$, potential evaporation $E_{\mathrm{p}}=120,000\left(\mathrm{~W} \mathrm{~m}^{-2}\right)$; and e 10-m wind speed = $60 \mathrm{~m} \mathrm{~s}^{-1}$, droplet radius $=500 \mu \mathrm{m}$, mass of the droplets $=8 \times 10^{-2} \mathrm{~kg} \mathrm{~m}^{-2} \mathrm{~s}^{-1}$, and potential evaporation $E_{\mathrm{p}}=200,000\left(\mathrm{~W} \mathrm{~m}^{-2}\right)$. Some curves cannot be identified because the values are very close

becomes more obvious, particularly when the modified thermal effect is used together with the impact on momentum generated by the presence of sea-spray (green line). Overall the droplet loading decreases (or increases) momentum flux below (or above) the droplet-ejection level. The maximum in the vertical momentum flux above the spray ejection level $(7 \mathrm{~m})$ is associated with the enhanced momentum mixing due to the droplet mass-loading. The decrease of the mean wind speed by mass-loading increases the vertical shear of the mean wind above and below the ejection level and thus gives rise to the maximum. The buoyancy increase accompanying the initial cooling of droplets also contributes to the maximum. It is important to point out that the momentum flux can be regarded as height-independent above $20 \mathrm{~m}$, consistent with what is revealed in Fig. 5 that the Monin-Obukhov similarity relations should only be valid in the surface layer above the elevation where wave breaking takes places. This result suggests that a displacement associated with the significant wave height should be included in the Monin-Obukhov similarity relation for surface flux calculation in numerical models used for tropical storm prediction. 
Fig. 5 Vertical profiles of heat fluxes (left sensible; right latent) associated with various feedback effects of sea-spray for a 10-m wind speed $=25 \mathrm{~m} \mathrm{~s}^{-1}$, droplet radius $=200 \mu \mathrm{m}$, mass of the droplets $=$

$8.4 \times 10^{-4} \mathrm{~kg} \mathrm{~m}^{-2} \mathrm{~s}^{-1}$, and potential evaporation $E_{\mathrm{p}}=2,100$ $\left(\mathrm{W} \mathrm{m}^{-2}\right)$; b 10- $\mathrm{m}$ wind speed $=$ $30 \mathrm{~m} \mathrm{~s}^{-1}$, droplet radius $=$ $256 \mu \mathrm{m}$, mass of the droplets $=$ $2.4 \times 10^{-3} \mathrm{~kg} \mathrm{~m}^{-2} \mathrm{~s}^{-1}$, and potential evaporation $E_{\mathrm{p}}=6,000$ $\left(\mathrm{W} \mathrm{m}^{-2}\right)$; $\mathbf{c} 10-\mathrm{m}$ wind speed $=$ $40 \mathrm{~m} \mathrm{~s}^{-1}$, droplet radius $=$ $360 \mu \mathrm{m}$, mass of the droplets $=$ $1.2 \times 10^{-2} \mathrm{~kg} \mathrm{~m}^{-2} \mathrm{~s}^{-1}$, and potential evaporation $E_{\mathrm{p}}=$ 30,000 $\left(\mathrm{W} \mathrm{m}^{-2}\right)$; d 10-m wind speed $=50 \mathrm{~m} \mathrm{~s}^{-1}$, droplet radius $=450 \mu \mathrm{m}$, mass of the droplets $=4.8 \times 10^{-2} \mathrm{~kg} \mathrm{~m}^{-2} \mathrm{~s}^{-1}$, potential evaporation $E_{\mathrm{p}}=$ $120,000\left(\mathrm{~W} \mathrm{~m}^{-2}\right)$; and e $10-\mathrm{m}$ wind speed $=60 \mathrm{~ms}^{-1}$, droplet radius $=500 \mu \mathrm{m}$, mass of the droplets $=8 \times 10^{-2} \mathrm{~kg} \mathrm{~m}^{-2} \mathrm{~s}^{-1}$, and potential evaporation $E_{\mathrm{p}}=$ $200,000\left(\mathrm{~W} \mathrm{~m}^{-2}\right)$. Some curves cannot be identified because the values are very close
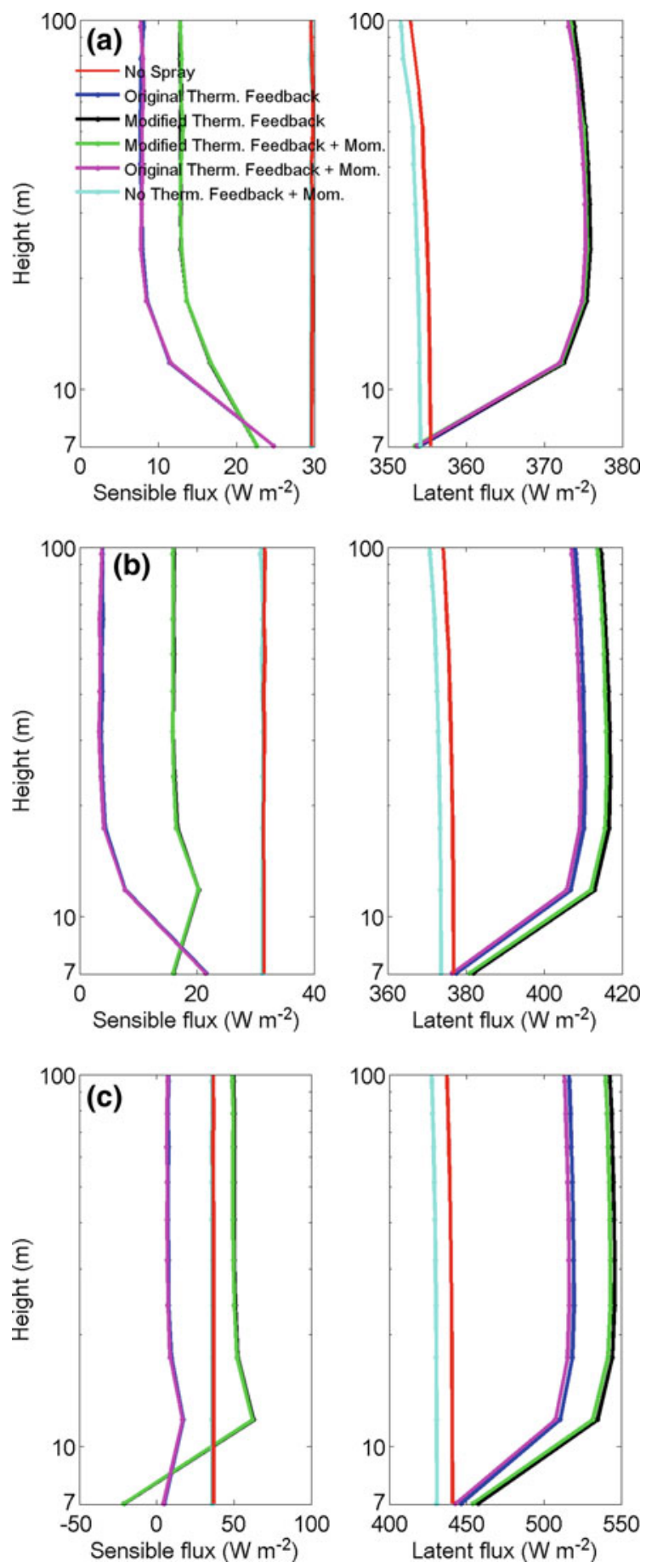
Fig. 5 continued
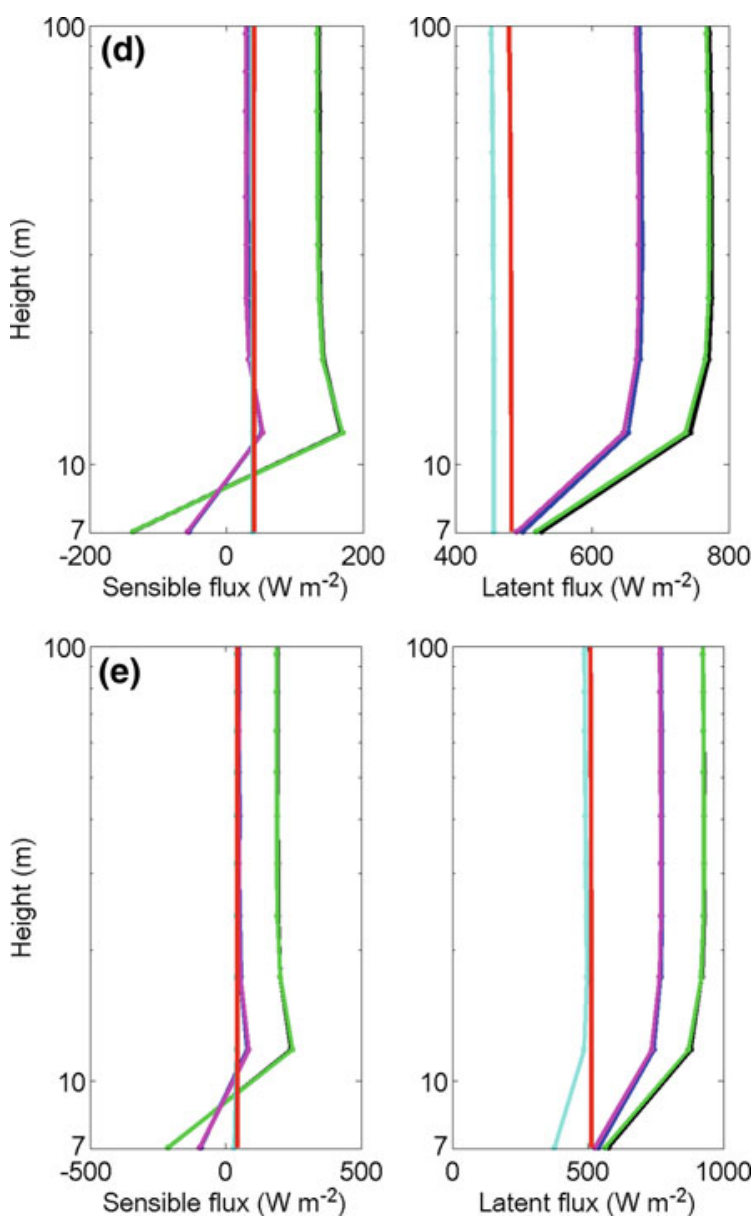

To further demonstrate the impact of droplet loading on the surface drag associated with the droplet-mediated changes in momentum flux, the droplet-mediated changes in the friction velocity are shown in Fig. 7. The exchange of heat and momentum between the ocean surface and the atmosphere varies with different $10-\mathrm{m}$ wind speeds, corresponding to the results shown previously. The impact on the friction velocity, $u_{*}$, caused by the thermal feedback is to increase its value, but the increase by the original thermal feedback is slight. On the other hand, the momentum effect of droplet loading tends to decrease $u_{*}$. This leads to different behaviour of the transfer coefficient of momentum, $C_{\mathrm{D}}$, which can be computed as $u_{*}^{2} / u_{10}^{2}$. For all the cases analyzed here, the behaviour of $C_{\mathrm{D}}$ as a function of the $10-\mathrm{m}$ wind speed (not shown) presents a reduction in the transfer coefficient of momentum values at high wind speeds relative to the case of no-spray effects. This behaviour of $C_{\mathrm{D}}$ as a function of the $10-\mathrm{m}$ wind is consistent with recent observations (Powell et al. 2003) and the newly developed surface resistance law (Makin 2005), both of which show that the drag coefficient is reduced at hurricane winds.

It should be pointed out that the mechanism of decreasing $u_{*}$ when the original thermal feedback is used is the same as the simulation in which the momentum effect of droplet loading is taken into account: to change the stability (i.e. making it more stable) in the 
Fig. 6 Vertical profiles of momentum flux associated with various feedback effects of sea-spray for a 10-m wind speed $=25 \mathrm{~m} \mathrm{~s}^{-1}$, droplet radius $=$ $200 \mu \mathrm{m}$, mass of the droplets $=$ $8.4 \times 10^{-4} \mathrm{~kg} \mathrm{~m}^{-2} \mathrm{~s}^{-1}$, and potential evaporation $E_{\mathrm{p}}=2,100$ $\left(\mathrm{W} \mathrm{m}^{-2}\right)$; b 10-m wind speed $=$ $30 \mathrm{~m} \mathrm{~s}^{-1}$, droplet radius $=$ $256 \mu \mathrm{m}$, mass of the droplets $=$ $2.4 \times 10^{-3} \mathrm{~kg} \mathrm{~m}^{-2} \mathrm{~s}^{-1}$, and potential evaporation $E_{\mathrm{p}}=6,000$ $\left(\mathrm{W} \mathrm{m}^{-2}\right)$; $\mathbf{c} 10-\mathrm{m}$ wind speed $=$ $40 \mathrm{~m} \mathrm{~s}^{-1}$, droplet radius $=$ $360 \mu \mathrm{m}$, mass of the droplets $=$ $1.2 \times 10^{-2} \mathrm{~kg} \mathrm{~m}^{-2} \mathrm{~s}^{-1}$, and potential evaporation $E_{\mathrm{p}}=$ 30,000 $\left(\mathrm{W} \mathrm{m}^{-2}\right)$; d 10-m wind speed $=50 \mathrm{~m} \mathrm{~s}^{-1}$, droplet radius $=450 \mu \mathrm{m}$, mass of the droplets $=4.8 \times 10^{-2} \mathrm{~kg} \mathrm{~m}^{-2} \mathrm{~s}^{-1}$, potential evaporation $E_{\mathrm{p}}=$ $120,000\left(\mathrm{~W} \mathrm{~m}^{-2}\right)$; and e 10-m wind speed $=60 \mathrm{~m} \mathrm{~s}^{-1}$, droplet radius $=500 \mu \mathrm{m}$, mass of the droplets $=8 \times 10^{-2} \mathrm{~kg} \mathrm{~m}^{-2} \mathrm{~s}^{-1}$, and potential evaporation $E_{\mathrm{p}}=$ $200,000\left(\mathrm{~W} \mathrm{~m}^{-2}\right)$. Some curves cannot be identified because the values are very close
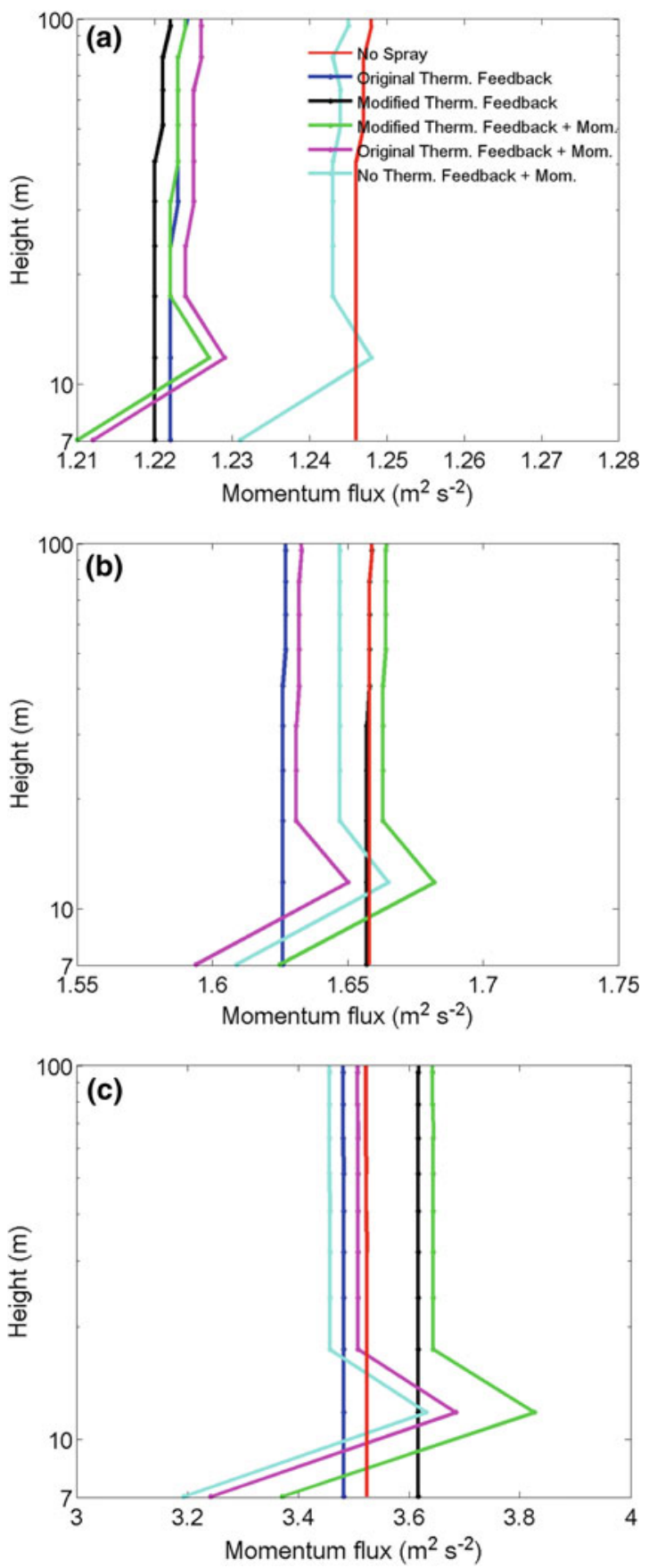
Fig. 6 continued
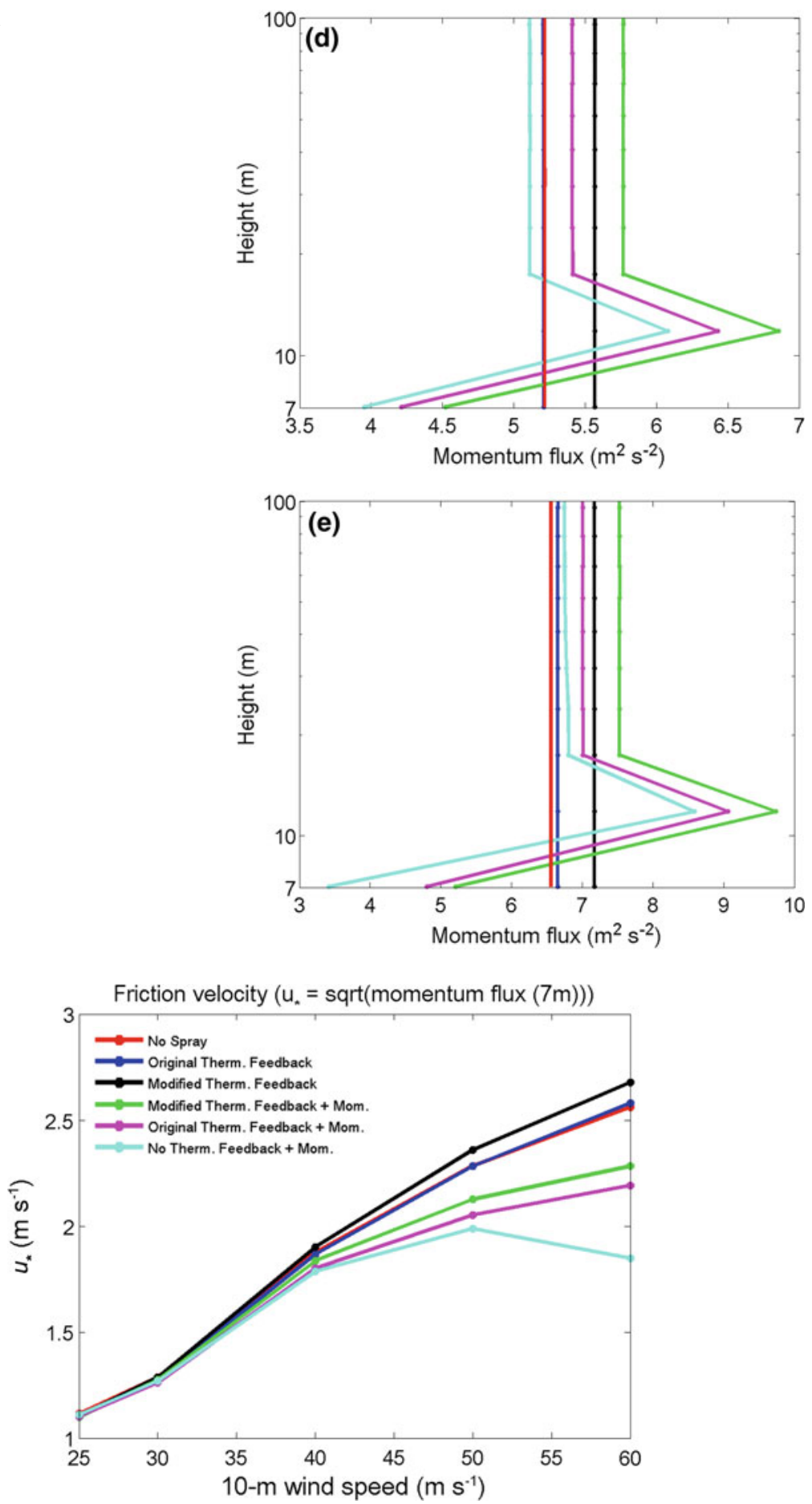

Fig. 7 Values of $u_{*}$ associated with various feedback effects of sea-spray as a function of the 10-m wind speed 
atmospheric surface layer right above the elevation of wave breaking. However, the way in which the stability changes in the simulation with the original thermal feedback is different than the simulation with the momentum effect of droplet loading: The former cools the temperature through overestimated evaporation while the latter changes the total density profile through droplet loading.

\section{Summary and Conclusions}

In this study, an explicit sea-spray droplet model is coupled with a 1-D surface-layer model to investigate and quantify the effects of sea-spray droplets on the mean winds, the stability of the surface layer, and the balance of turbulent kinetic energy. The droplet-laden surfacelayer model takes into account the effects of turbulent mixing, freefall, and evaporation of sea-spray droplets on the momentum and heat exchanges across the spray-filled part of the surface layer. The sea-spray generation rate is modeled by a source function developed based on laboratory experiments and observations made in nature. A number of simulations are performed using the model, and the following are the major conclusions based on the results from these simulations.

First, the overall impact of sea-spray droplets on the mean winds depends on the wind speed at the level of sea-spray generation. As the wind speed increases, the droplet size increases and the overall wind speed in the surface layer above the level of sea-spray generation increases, indicating that the increase of droplet size due to the increase of wind speed enhances the vertical mixing.

Second, when the wind is below $40 \mathrm{~m} \mathrm{~s}^{-1}$, the droplets are small in size and tend to evaporate substantially and thus cool the spray-filled layer. When the wind is above $50 \mathrm{~m} \mathrm{~s}^{-1}$, the size of the droplets is so big that they do not have enough time to evaporate that much before falling back into the sea. Effectively, the sensible heat carried by the droplets is released to the ambient air, increasing the buoyancy of the surface layer and enhancing the turbulent mixing.

Third, the turbulent suspension of sea-spray droplets reduces the buoyancy and makes the surface layer more stable. As a consequence, the friction velocity is lowered and the downward turbulent mixing of momentum is reduced.

Lastly, the results from the simulations in which spray droplets are taken into account strongly suggest that a displacement equal to the mean wave height should be included in the logarithmic profiles of wind and thermal fields not to violate the constant flux assumption critical to the Monin-Obukhov similarity theory behind the logarithmic relations.

All these conclusions are based on the 1-D model simulations and our interpretation of the numerical results from the simulations. Although there are few observations available under high winds that can be used for the model evaluation, the results from the model simulations provide a theoretically possible mechanism responsible for the reduction of the sea-surface drag at high winds, which is supported by acceptable observational evidence. There are indeed limitations in these conclusions due to the 1-D model's simplified treatment of the complicated physics between suspended sea-spray droplets and turbulence in the droplet-filled atmospheric surface layer. Thus, while we believe that the qualitative characteristics of the conclusions are physically and dynamically reasonable, we wish to caution that future observations, along with the increasing theoretical understanding of the subject, will alter some quantitative aspects of the conclusions. For example, the numerical results presented in this article are subject to uncertainties in the fall speed calculation. 
In this study, the formulation for the so-called terminal fall speed is used to estimate the fall speed at a given elevation for a given size of droplets. It may not be appropriate to assume that all the droplets will reach the steady terminal fall speed before they fall back into the sea. There are also uncertainties in the spray generation function. Detailed laboratory experiments are needed to reduce these uncertainties. Better formulations for the spray generation and the fall speed based on future detailed experimental data will certainly modify the quantitative aspects of the above conclusions. Finally, the sea-surface temperature was set to $300 \mathrm{~K}$ (higher than the surface air temperature) in all the experiments. The sea surface is not always warmer than the air, e.g. when tropical storms move away from their generation region in the tropics and pass over areas at higher latitudes where the sea surface is often cooler than the air. Further study with the 1-D model is required to understand what the effects of having a sea surface colder than the air would be on air-sea momentum and heat fluxes.

Acknowledgments The authors wish to acknowledge the anonymous reviewers for providing extremely useful suggestions to improve the manuscript. This study is supported by the Hurricane Forecasting Improvement Project (HFIP) of NOAA.

Open Access This article is distributed under the terms of the Creative Commons Attribution Noncommercial License which permits any noncommercial use, distribution, and reproduction in any medium, provided the original author(s) and source are credited.

\section{References}

Andreas EL (1989) Thermal and size evolution of sea-spray droplets. CRREL Rep. 89-11. U.S. Army Cold Regions Research and Engineering Laboratory, Hanover, NH, 37 pp

Andreas EL (1990) Time constants for the evolution of sea-spray droplets source. Tellus 42:481-497

Andreas EL (1995) The temperature of evaporating sea-spray droplets. J Atmos Sci 52:852-862

Andreas EL, Emanuel KA (2001) Effect of sea-spray on tropical cyclones intensity. J Atmos Sci 58:3741-3751

Anthes RA (1982) Tropical cyclones: their evolution, structure, and effects. Meteorological Monographs No. 41. American Meteorological Society, Boston, MA, 208 pp

Bao J-W, Wilczak JM, Choi JK, Kantha LH (2000) Numerical simulations of air-sea interaction under high wind conditions using a coupled model: a study of hurricane development. Mon Weather Rev 128: 2190-2210

Barenblatt GI (1979) Similarity, self-similarity, and intermediate asymptotic. Consultant Bureau, Plenum Press, New York, 218 pp

Barenblatt GI (1996) Scaling, self-similarity, and intermediate asymptotics. Cambridge University Press, Cambridge, UK, 386 pp

Bintanja R (2000) Snowdrift suspension and atmospheric turbulence. Part I: theoretical background and model description. Boundary-Layer Meteorol 95:343-368

Black PG, Burpee RW, Dorst NM, Adams WL (1986) Appearance of the sea surface in tropical cyclones. Wea Forecast 1:102-107

Braun SA, Tao W-K (2000) Sensitivity of high-resolution simulation of Hurricane Bob (1991) to planetary boundary layer parameterizations. Mon Weather Rev 128:3941-3961

Emanuel KA (1995) Sensitivity of tropical cyclones to surface exchange coefficients and a revised steady-state model incorporating eye dynamics. J Atmos Sci 52:3969-3976

Fairall CW, Kepert JD, Holland GJ (1994) The effect of sea-spray on surface energy transports over the ocean. Glob Atmos Ocean Syst 2:121-142

Fairall CW, Banner ML, Peirson WL, Asher W, Morison RP (2009) Investigation of the physical scaling of sea-spray spume droplet production. J Geophys Res 114:Article Number: C10001

Gall JS, Frank WM, Kwon Y (2008) Effects of sea-spray on tropical cyclones simulated under idealized conditions. Mon Weather Rev 136:1686-1705

Kepert JD (1996) The temperature of evaporating sea-spray droplets-comments. J Atmos Sci 53:1634-1641

Kepert JD, Fairall CW (1999) On the parameterization of spray fluxes for tropical cyclones. In: Extended abstracts, 23rd conference on Hurricanes and tropical meteorology, Dallas, TX, Jan 10-15, American Meteorological Society, pp 145-148 
Kepert JD, Fairall CW, Bao J-W (1999) Modelling the interaction between the atmospheric boundary layer and evaporating sea-spray droplets. In: Geernaert GL (ed) Air-sea exchange: physics, chemistry and dynamics. Kluwer, Dordrecht, pp 363-407

Lykossov V (2001) Atmospheric and oceanic boundary layer physics. In: Jones ISF, Toba Y (eds) Wind stress over the ocean. Cambridge University Press, Cambridge, pp 58-81

Makin VK (2005) A note on the drag of the sea surface at hurricane winds. Boundary-Layer Meteorol 115: 169-176

Makin VK, Kudryavtsev VN, Mastenbroek C (1995) Drag of the sea-surface. Boundary-Layer Meteorol 73:159-182

Mellor GL, Yamada T (1982) Development of a turbulence closure-model for geophysical fluid problems. Rev Geophys Space Phys 20:851-875

Monin AS, Obukov AM (1954) The basic regularities of turbulent mixing in the atmospheric surface layer. Tr Akad Nauk SSSR Geofiz Inst 24:163-187

Powell MD, Vickery PJ, Reinhold TA (2003) Reduced drag coefficient for high wind speeds in tropical cyclones. Nature 422:279-283

Rouault MP, Mestayer PG, Schiestel R (1991) A model of evaporating spray droplet dispersion. J Geophys Res 96:7181-7200 